\title{
Assessment of primary school students' decision-making related to tactical contexts
}

\author{
David Gutiérrez ${ }^{1,}$, Luis Miguel García-López² \\ ${ }^{1}$ Facultad de Educación, Universidad de Castilla La-Mancha, Spain \{david.gutierrez@uclm.es\} \\ 2Facultad de Educación, Universidad de Castilla La-Mancha, Spain \{luismiguel.garcia@uclm.es\} \\ Received on 13 January 2012; revised on 3 February 2012; accepted on 19 February 2012; published on 15 July 2012
}

DOI: $10.7821 /$ naer.1.1.7-12

\begin{abstract}
The purpose of this study was to assess and understand prior tactical knowledge and game performance as well as the relationship between the different components of game performance in invasion games. The participants ( $N=22$; girls: 13 ; boys: 9 ) were Physical Education students (ages: 11-12) with a low expertise in invasion games (they were selected among those with no other background in invasion games than PE lessons). Their game performance was videotaped, after which measures of motor execution and cognitive components were developed from observational analysis. Decision- making was measured on two levels: a) decision-making restricted to the performance of technicaltactical skills; and b) decision-making focused on adapting to the offensive tactical contexts of the game. Participants played an eight-minute-long 4-versus-4 generic invasion game. The latter was designed to meet both developmental needs and previous learning, so interference between motor execution ability and decision-making performance was minimized. The findings revealed that these students already had a basic concept of offensive and defensive game situations, both on-the-ball and off-theball. No significant differences were found between players' performance in penetrating-the-defense contexts and in those where they kept ball possession. The findings additionally highlighted the existence of significant relationships between decision-making and skill execution in getting open, tackling, marking off-ball and double teaming. Other links between game performance components are discussed throughout the paper. The importance of assessing game performance taking into account tactical contexts is also supported (Gutiérrez, González, García-López, \& Mitchell, 2011), as well as some of the GCA pedagogical principles, e.g. the use of modified games (Oslin \& Mitchell, 2006).
\end{abstract}

KEYWORDS: EVALUATION METHODS; PERFORMANCE BASED ASSESSMENT; PRIOR LEARNING; PHYSICAL EDUCATION; TEAM SPORTS.

\section{INTRODUCTION}

Important changes have happened in instructional theories during the last decades. These theories have moved from being based on behavioural theories to being based on constructivist theories, and from associative learning to constructivist learning. In games teaching, the traditional and still most widespread approach is the technical model based on the acquisition of isolated skills. Following the changes that have taken place in most curricular areas, including Physical Education, this traditional approach should be replaced by approaches founded on constructivism, the ecological paradigm and a situated learning perspective. Although this change has been taking place for several years, it is still more evident in the published literature than in real practice (Robles, Giménez, \& Abad, 2011). Alternative teaching games methodology has been gathered by Oslin and Mitchell (2006) under the denomination of GameCentered Approaches (GCAs). GCAs comprise the original and most well-known model: Teaching Games for Understanding (Bunker \& Thorpe, 1982, 1986) and the following evolutions such as the Tactical Game Model (Griffin, Mitchell, \& Oslin, 1997) or Play Practice (Launder, 2001). The description made of GCAs by Oslin and Mitchell (2006) is very close to that used in Spain to designate alternative approaches. In Spain GCAs are gathered under the name Enseñanza Comprensiva del Deporte.

Game-centered approaches contain features that make these models superior to the traditional model. Oslin and Mitchell (2006) summarized them in four main features: (1) children are motivated by games; (2) potential transfer based on tactical similarities (García-López, Contreras, Penney, \& Chandler, 2009); (3) development of decision-making component, and (4) development of decision makers through a problem solving approach. To make the most of the formative potential of GCAs, the observation of three features is of great importance: 1) authentic assessment, 2) teaching progressions based on tactical aspects; and 3) importance of previous learning on the selection of contents and on the design of progressions. As stated below, the second and third features aforementioned have not been sufficiently linked by critical studies. The main reason for this gap is the lack of research data about previous learning on which to base learning progressions. The aim of this paper is to contribute to lessen this limitation.

In comparison to the traditional approaches, in GCAs more pedagogical importance has been given to the assessment process. There is evidence of the importance given to assessment in GCAs in the development of observational instruments to assess game performance during actual game play. Examples of these instruments are Game Performance Assessment Instruments (GPAI) (Oslin, Mitchell, \& Griffin, 1998), Team Sport Assessment Procedures (TSAP) (Gréhaigne, Godbout, \& Boutier, 1997) and those designed by Blomqvist, Vänttinen, and Luhtanen (2005) or French and Thomas (1987). Most of these instruments have been used in both research and physical 
education settings. Through these instruments, game performance components, decision making and skill execution are evaluated separately. As GCAs have as their central premises the game and the decision-making component (Oslin \& Mitchell, 2006), this kind of assessment provides researchers and teachers with very valuable and useful information to improve the learning process. In this sense, when the assessment procedure links what is taught to how it is taught, it helps to regulate the teaching and the learning process. This kind of assessment is generally known as authentic assessment (Memmert \& Harvey, 2008).

Both cognitive and motor components are equally important in developing sport performance (French \& Thomas, 1987; Griffin, Dodds, Placek, \& Tremino, 2001), and therefore they should have the same importance in the assessment process. Furthermore, these components are highly difficult to separate during game play. As Nevett, Rovegno, Babiarz, and McCaughtry (2001) suggest, a player's motor coordination is determined by individual, environmental and task constrains, so skill and tactics should not be separated. Consequently, in further discussions about skills such as passing, getting open, or marking, we will refer to them as technical-tactical skills.

Furthermore, GCAs use structural features (rules, space, materials, etc.) and tactical problems to design task and learning progressions. Previous literature has suggested different proposals to classify tactical problems. Probably the most widespread are those made by Griffin, Mitchell, and Oslin (Griffin et al., 1997 for specific games such as football, basketball, etc.; and Mitchell, Oslin, \& Griffin, 2003 for game categories such as invasion games, net games, etc.). These authors establish the different tactical goals and problems to guide the teaching and learning process. For invasion games, the tactical goals and problems proposed are: a) within offensive and scoring: keeping possession, penetrating and attacking, and transition; b) within defense and preventing scoring: defending space, defending the goal, and winning the ball; and c) within starting and restarting play: beginning the game, restarting from the sideline and endline, and restarting from violations. Another tactical problem classification is that inspired on the action principles described by Bayer (1986). This author considers three action principles in attack (maintaining possession of the ball, penetrating the defense, and attacking the goal) and three in defense (recovering possesion of the ball, defending space and defending the goal). Bayer does not describe these action principles as tactical problems, but as game context. Nevertheless they have been used as tactical problems in the design of activities books (e.g. Contreras, García-López, Gutiérrez, del Valle, \& Aceña, 2007; Contreras, de la Torre, \& Velázquez, 2001) and in research works (e.g. González, GarcíaLópez, Gutiérrez, \& Contreras, 2010; Gutiérrez et al., 2011).

The third feature that should observe GCAs to maximize their pedagogical potential is to base learning tasks and progressions in the learners' previous knowledge. As learners bring with them previous experiences and knowledge to the lessons, they base and negotiate the meaning of the learning experiences from their existing schema by revising and creating understanding out of existing ones (Applefield, Huber, \& Moallem, 2001). Different studies have addressed this issue (e.g. Nevett et al., 2001, Blomqvist et al., 2005), using in most cases a knowledge-based information-processing perspective as their theoretical framework.

This study has the aim to add valuable information to reduce the aforementioned limitations. A coding instrument was designed and used to assess decision making components in the two levels described. Therefore, the purpose of the study is twofold: to devise and implement a "game context" approach to assess the game performance components and, doing so, to provide information that could be used to design suitable learning progressions linked with tactical teaching approaches.

\section{METHODOLOGY}

\subsection{Participants and procedure}

This research has been carried out within a collaborative project between the University of Castilla-La Mancha and the educational government of this region. The sample included 22 elementary school Physical Education students (girls: 13; boys: 9; ages: 11-12 years). Participants were selected from among students with no formal training in invasion games and without any experience in official competition. Participants were evaluated through a 4 versus 4 invasion game, where the technical and rules requirements were minimized. The game form was selected following the developmental abilities and previous experience in such a way that students would be able to reach their maximum achievement in the decision making component. Selection of the number of players per team was based on the proposal made by Mitchell et al. (2003).

The design of the modified invasion game was inspired by those used in similar research made in educational contexts (Contreras, García-López, \& Cervelló, 2005; Blomqvist et al., 2005; Nevett et al., 2001). All games lasted 8 minutes and were divided into two halves. All games were recorded with a video camera located behind and above the court and were analysed afterwards using the G-PET (Game Performance Evaluation Tool).

\subsection{Coding Instrument: G-PET (Game Performance Evaluation Tool)}

A coding instrument was used to examine the components of game performance and game play features. The design for GPET (Gutiérrez, 2008) was based on the instruments designed by French and Thomas (1987) and Nevett et al. (2001). Most relevant variations from these instruments were the analysis of defensive actions and the tactical-context adaptation. Content validity was established by a panel of experts. Instrument reliability was established through test-retest procedures, with correlation coefficients higher than .80. Intra- and inter-observer correlations among the observers in all categories ranged from .77 to 1.00 .

Skill execution was judged as successful (1) or unsuccessful (0) in every execution. Decision-making was analysed into two levels. In both levels right decision-making was coded as (1), and wrong as $(0)$. The first level evaluated decision-making related to the execution of a specific skill or movement (e.g. a correct decision-making (1) would be to pass the ball to a playmate who is free, and a wrong one (0) would be to move trying to get free to a space where one opponent is standing). The second level analysed the tactical-context adaptation trough the evaluation of players' tactical intention with regard to the tactical context in which the action is located. This level was established only for offensive actions. Based on Bayer action principles (1986), G-PET includes three offensive tactical contexts: maintaining possession of the ball (1A), penetrating the defense (2A), and attacking the goal (3A). For coding purposes, tactical contexts were coded respectively as $1 \mathrm{~A}, 2 \mathrm{~A}$ or $3 \mathrm{~A}$. These abbreviations will be used throughout the paper. 
When an action was analysed, researchers first evaluated in which tactical context the action took place, or the situated principle (it could be coded as $1 \mathrm{~A}, 2 \mathrm{~A}$ or $3 \mathrm{~A}$ and written down in first place), and then they evaluated the intention of the player or the applied principle (it could be coded as well as 1A, 2A or $3 \mathrm{~A}$ and written down in the second place). When the situated principle and the applied principle match, the tactical-context adaptation is correct. An example of correct adaptation to the tactical context would be: the player is trying to keep possession (by passing or moving with the ball) in a maintainingpossession-of-the-ball context. This action would be coded as 1A1A. An example of wrong adaptation could be: the player is trying to attack the goal (by shooting) in a penetrating-thedefense context. This second action (2A3A) would be coded as wrong. The actions in which the player showed neither tactical intention nor involvement on the game were also coded as wrong. This behaviour was coded as "watcher player".

Table 1 summarizes and describes the coding categories. Both first level decision-making and skill execution were evaluated in the technical-tactical skills included in the first column. These variables are presented by game roles. In order to get a clearer comparison of different game aspects, variables related to technical-tactical skills were grouped in global variables (defense; attack; on the ball; and off the ball). The second column includes variables related to the second level of decision making: tactical-context adaptation. Tactical-context-adaptation performance was grouped in a single variable (global-contextadaptation performance) and also analysed by the three offensive tactical contexts aforementioned.

Table 1: Description of the dependent variables to measure decisionmaking

\begin{tabular}{|c|c|}
\hline $\begin{array}{l}\text { Skill execution and } \\
\text { Level } 1 \text { Decision- } \\
\text { making: Technical- } \\
\text { tactical skill selection } \\
\end{array}$ & $\begin{array}{l}\text { Level } 2 \text { Decision-making: } \\
\text { Tactical-context adaptation }\end{array}$ \\
\hline $\begin{array}{l}\text { On-the-ball attacker } \\
\text { Pass } \\
\text { Shoot } \\
\text { Moving with the ball }\end{array}$ & $\begin{array}{l}\text { Global-context-adaptation performance } \\
\text { (Global efficiency during the whole game in } \\
\text { adapting the actions to the tactical context) }\end{array}$ \\
\hline $\begin{array}{l}\text { Off-the-ball attacker } \\
\text { Get free }\end{array}$ & $\begin{array}{l}\text { 1A1A. Tactical-context-adaptation } \\
\text { performance to keep the ball contexts } \\
\text { (efficiency in selecting actions to keep the } \\
\text { ball when the tactical context is coded as } \\
\text { "keeping the ball context") }\end{array}$ \\
\hline $\begin{array}{l}\text { On-the-ball defender } \\
\text { Mark (on-the-ball) } \\
\text { Blocked shot } \\
\text { Tackle } \\
\text { Double team (on-the- } \\
\text { ball) }\end{array}$ & $\begin{array}{l}\text { 2A2A. Tactical-context-adaptation } \\
\text { performance to penetrating-the-defense } \\
\text { contexts (efficiency in selecting actions to } \\
\text { penetrate the defense when the tactical } \\
\text { context is coded as "penetrating-the- } \\
\text { defense") }\end{array}$ \\
\hline $\begin{array}{l}\text { Off-the-ball defender } \\
\text { Mark (off-the-ball) } \\
\text { Interception } \\
\text { Double team (off-the } \\
\text { ball) }\end{array}$ & $\begin{array}{l}\text { 3A3A. Tactical-context-adaptation } \\
\text { performance to attacking the goal contexts } \\
\text { (efficiency in selecting actions to try to } \\
\text { score when the tactical context is coded as } \\
\text { "attacking the goal context") }\end{array}$ \\
\hline $\begin{array}{l}\text { Global variables } \\
\text { Defense/attack } \\
\text { On the ball / off the ball }\end{array}$ & $\begin{array}{l}\text { Watcher player (a player is coded as } \\
\text { "watcher player" when he or she does not } \\
\text { show tactical intention nor involvement in } \\
\text { the game) }\end{array}$ \\
\hline
\end{tabular}

For coding purposes, the playing time was divided into decision-making units of action (Nevett et al., 2001). The ending of a decision-making unit occurred in the following conditions: a) after four seconds of action; b) when the player performed a different technical-tactical skill; or c) when the offensive tactical context changed.

\subsection{Statistical analysis}

The mean and standard deviation were calculated for each variable. The Kolgomorov-Smirnov test for assumption of normality and the Levene test for homogeneity of variance or homoscedasticity showed that the sample did not meet these assumptions for all the variables in the study. Therefore and also due to a small sample size, a Mann-Whitney $U$ test was conducted to analyse the differences between the two samples. Wilcoxon's test was conducted for the two dependent samples. Lastly, the relationships between decision-making and skill execution were examined by using Pearson's correlation coefficient (Vincent, 2005).

\section{RESULTS}

The results are presented in three sections. The first section of the results will focus on descriptive scores of game performance. The second section will include four intra-group data analyses: (a) comparison of tactical context adaptation performances; (b) comparison of offensive skills performance (pass, move with the ball and get free) in different tactical contexts; (c) study of the correlation between decision making and skill execution; and (d) comparison between global variables: attack/defense; on the ball/off the ball.

\subsection{Descriptive scores of game performance}

Descriptive scores of game performance are depicted in Table 2.

Tactical-context-adaptation performance. Participants achieved a global context-adaptation performance of $62.97 \%$ $(S D=17.15)$ of good decisions. The context in which participants achieved better performance was in penetrating-thedefense $(M=70.08, S D=18.13)$, while the lowest performance was in attacking-the-goal $(55.41, S D=39.03)$. Participants did not show tactical intention nor involvement on the game (watcher players) in a $5.72 \%$ of the decision-making units.

Offensive technical-tactical skills. In decision making variables, highest scores were achieved in passing $(M=83.5, S D$ $=22.04)$ and shooting $(M=93.1, S D=13.70)$, while the lowest result was found in moving with the ball $(M=49.42, S D=$ 25.91). In skill execution, highest scores were found in control $(M=88.49, S D=20.27)$, and in moving with the ball $(M=$ $89.41, S D=13.97)$. The lowest results in skill execution were found in getting free $(M=59.72, S D=18.14)$.

Defensive technical-tactical skills. In decision-making variables, highest scores were achieved in blocking $(M=94.16$, $S D=15.05)$ and interceptions $(M=92.4, S D=17.26)$. Very low scores were achieved in marking skill execution, both on the ball $(M=29.79, S D=17.04)$ and off the ball $(M=31.05, S D=$ 19.05). 
Table 2: Percentages of efficiency in game performance variables

\begin{tabular}{|c|c|c|c|c|}
\hline Variable & \multicolumn{2}{|c|}{$M$} & \multicolumn{2}{|c|}{$S D$} \\
\hline Tactical-context adaptation & & & & \\
\hline Tactical-context-adaptation performance to keep-the-ball context (1A1A) & \multicolumn{2}{|c|}{62.97} & \multicolumn{2}{|c|}{17.15} \\
\hline $\begin{array}{l}\text { Tactical-context-adaptation performance to penetrating-the-defense } \\
\text { context }(2 \mathrm{~A} 2 \mathrm{~A})\end{array}$ & \multicolumn{2}{|c|}{70.08} & \multicolumn{2}{|c|}{18.13} \\
\hline Tactical-context-adaptation performance to attacking-the-goal (3A3A) & \multicolumn{2}{|c|}{55.41} & \multicolumn{2}{|c|}{39.03} \\
\hline Global-context-adaptation performance & \multicolumn{2}{|c|}{66.81} & \multicolumn{2}{|c|}{11.08} \\
\hline Watcher player ( $\%$ of decision making units) & \multicolumn{2}{|c|}{5.42} & \multicolumn{2}{|c|}{7.39} \\
\hline \multirow{2}{*}{ Technical-tactical skills } & \multicolumn{2}{|c|}{ Skill execution } & \multicolumn{2}{|c|}{ Decision-making } \\
\hline & $\boldsymbol{M}$ & $S D$ & $M$ & $S D$ \\
\hline \multicolumn{5}{|l|}{ On-the-ball attacker } \\
\hline Control & 88.49 & 20.27 & & \\
\hline Pass & 70.87 & 28.80 & 83.50 & 22.04 \\
\hline Pass $1 \mathrm{~A}$ & 64.77 & 39.26 & 79.22 & 26.11 \\
\hline Pass 2A & 67.78 & 38.55 & 90.55 & 16.92 \\
\hline Moving with the ball & 89.41 & 13.97 & 49.42 & 25.91 \\
\hline Moving with the ball $1 \mathrm{~A}$ & 90.48 & 14.11 & 72.96 & 31.54 \\
\hline Moving with the ball $2 \mathrm{~A}$ & 92.11 & 25.69 & 39.78 & 35.86 \\
\hline Shoot & 83.12 & 20.80 & 93.12 & 13.70 \\
\hline \multicolumn{5}{|l|}{ Off-the-ball attacker } \\
\hline Get free & 59.72 & 18.14 & 71.54 & 15.57 \\
\hline Get free $1 \mathrm{~A}$ & 57.50 & 32.01 & 66.61 & 24.79 \\
\hline Get free $2 \mathrm{~A}$ & 58.91 & 22.30 & 72.39 & 19.03 \\
\hline \multicolumn{5}{|l|}{ On-the-ball defender } \\
\hline Mark (on-the-ball) & 29.79 & 17.04 & 62.27 & 24.55 \\
\hline Blocked shot & 43.75 & 40.29 & 94.16 & 15.05 \\
\hline Tackle & 50 & 50 & 55 & 49.72 \\
\hline Double team (on-the-ball) & 71.42 & 48.79 & 85.71 & 37.79 \\
\hline \multicolumn{5}{|l|}{ On-the-ball defender } \\
\hline Mark (off-the-ball) & 31.05 & 19.05 & 44.41 & 23.80 \\
\hline Interception & 71.66 & 37.60 & 92.42 & 17.26 \\
\hline Double team (off-the-ball) & 48.14 & 24.95 & 64.92 & 20.21 \\
\hline \multicolumn{5}{|l|}{ Global variables } \\
\hline Attack & 76.40 & 10.57 & 74.71 & 11.43 \\
\hline Defense & 51.15 & 8.04 & 71.44 & 8.41 \\
\hline On-the-ball & 64.90 & 9.35 & 75.63 & 9.20 \\
\hline Off-the-ball & 52.34 & 11.28 & 67.39 & 12.96 \\
\hline
\end{tabular}

\subsection{Intragroup analysis}

Comparison of tactical-context-adaptation performances. No significant differences were found between tactical-contextadaptation performance to keep the ball, penetrating the defense and attacking the goal contexts.

Comparison of decision-making and motor execution performance of offensive technical-tactical skills (passing, moving with the ball and getting free) in different tactical contexts (keep-the-ball and penetrating-the-defense contexts). Game performance efficiency in passing, moving with the ball and getting clear was analysed separately in a maintainingpossession-of-the-ball context and penetrating-the-defense context. When comparing both scores, significant differences (at $p<.05$ level) were found only in moving-with-the-ball decision making where participants showed significant better performance in the maintaining-possession-of-the-ball context.
Study of the correlation between decision making and skill executions. Decision making and motor execution correlated significantly (at $p<.01$ level) in one offensive technical-tactical skill (getting free) and three defensive skills (stealing the ball, marking off the ball and double teaming by the defender off the ball).

Comparison between global variables: attack/defense; on-theball off-the-ball. Participants performed significantly better onthe-ball skills. These differences were at $p<.05$ level in decision making, and at $p<.01$ level in skill execution. Students performed better in both the decision-making and the skill execution ability while attacking, although these differences were only statistically significant in the skill execution ability ( $p$ $<.01)$. Thus, participants found it more difficult to perform defensive actions than offensive ones, especially in relation to skill execution. 


\section{DISCUSSION}

The purpose of our study was to assess and understand prior procedural knowledge in sixth graders with no previous training in invasion games, as well as the relationship among the different components of game performance in invasion games.

Results revealed that 6th grade students got the highest tactical context adaptation performance in penetrating-thedefense contexts, and the worst in attacking-the-goal contexts. This means that students were able to decide better in situations in which the best option was to move towards the goal, either by passing or moving with the ball. This result is partly consistent with those presented by Gutiérrez, García-López, González, and Contreras (2008). In that study, secondary PE students (13-14 years old) in a 5 versus 5 modified invasion game achieved better adaptation results in a penetrating-the-defense context than in a keeping-possession-of-the-ball context, but the higher context adaptation performance was in attacking-the-goal contexts. These results also partially coincide with those found by González et al. (2010) in the context adaptation performance shown by soccer players of the same age as the participants in this study. Participants of both studies showed their best performance in penetrating-the-defense contexts, and the weakest scores in attacking-the-goal contexts, although soccer players scored better than PE students in all tactical contexts (for further information on the comparison of these two studies see Gutiérrez et al., 2011).

Participant scores in technical-tactical skills were quite inconsistent both in the comparison between different technicaltactical skills, and in the comparison of decision-making and execution performance in the same technical-tactical skill. In most of the variables participants scored higher in decisionmaking than in skill execution. Highest scores were achieved in blocking and interceptions, both in the decision-making component. These two technical-tactical skills are highly related, both technically and tactically. Thus, similar scores support the idea of transfer. Biggest differences between decision-making and skill execution were found in marking and blocking. The only exception was moving-with-the-ball, in which participants executed much better than they decided. The successes in skill execution in technical-tactical skills as blocking and marking depend to a great extent on the performance of the opponent. Therefore, the origin of these differences could be in the relational nature of the technical-tactical skills (Gutiérrez, García-Lopez, \& Contreras, 2009; MacPhail, Kirk, \& Griffin, 2008). On the other hand, the success of moving with the ball was facilitated by the rules, because there were no rules such a doubles, and physical contact was not allowed. In this sense, it seems that decision-making is more conditioned than skill execution by structural features, like opponents or rules. This is consistent with the idea of the importance of the use of modified games in teaching games supported in GCAs (Memmert \& Harvey, 2010; Oslin \& Mitchell, 2006; Serra, J., García-López, L. M., \& Sánchez-Mora, 2011).

Students got their best performance, both in decision-making and skill execution, in offensive and on-the-ball game actions. Same results were found by Blomqvist et al. (2005) who state that the origin of these results is that "instruction in physical education settings focuses mainly on motor skill execution, and thus, students' decision-making skills with-the-ball are more refined" (2005, p. 117).

In the comparison of decision-making and motor execution performance of offensive technical-tactical skills in different tactical contexts, participants showed a different performance just in moving with the ball. In this variable participants decided better in a keeping-possession-of-the-ball context than in a penetrating-the-defense context. These results indicate that when players were under pressure, they performed this skill adequately, and when they had to use it to penetrate the defense they did not make the right decision. Furthermore, in a penetrating-the-defense context they showed much more efficiency when passing $(90.55 \%)$, than when they chose to move with the ball $(39.78 \%)$. These results show that the tactical context in which the action takes place is important in the realization of the technical-tactical skill, and that tactical contexts have a higher influence over the decision making component.

These results are consistent with previous studies that used a tactical-context approach to assess game performance (e.g. Gonzalez et al., 2010; Gutiérrez et al., 2011).

The high correlation established between execution and decision-making and the low levels of efficiency in execution show the necessity of using modified games as a didactic resource. These results also show the suitability of proposing global teaching situations, as recommended in GCAs (Memmert \& Harvey, 2010; Oslin \& Mitchell, 2006).

Blomqvist et al. (2005) reported that their study had two limitations, the first was the skill heterogeneity of the participants, and the second was that all of them were boys. We tried to avoid these two limitations by selecting girls and boys and through the use of a questionnaire about previous experience, so that very skilful subjects were not assessed. However, high values in standard deviation were found in most of the variables, and therefore participants in our study had skill heterogeneity as well. In order to know the nature of these individual differences, more research is necessary in the line of that carried out by MacPhail et al. (2008) and Rovegno, Nevett, Brock, and Babiarz (2001), who applied a situated approach in order to know the influence of the social-interactive dimension in the teaching and learning of invasion games.

\section{REFERENCES}

Applefield, J., Huber, R., \& Moallem, M. (2001). Constructivism in theory and practice: Toward a better understanding. High School $\begin{array}{llll}\text { Journal, } & 84(2), & 35-53 . & \text { Retrieved from }\end{array}$ http://www.jstor.org/pss/40364404

Bayer, C. (1986). La enseñanza de los juegos deportivos colectivos. Barcelona: Hispano Europea.

Blomqvist, M., Vänttinen, T., \& Luhtanen, P. (2005). Assessment of secondary school students' decision-making and game-play ability in soccer. Physical Education and Sport Pedagogy, 10(2), 107-119. doi: $10.1080 / 17408980500104992$

Bunker, D., \& Thorpe, R. (1982). Model for the teaching of games in secondary schools. Bulletin of Physical Education, 18(1), 5-8.

Bunker, D., \& Thorpe, R. (1986). Is there a need to reflect on our games teaching? In R. Thorpe, R. Bunker \& L. Almond (Eds.), Rethinking games teaching (pp. 25-34). Loughborough: Dept. of Physical Education and Sports Science.

Contreras, O. R., García-López, L. M., \& Cervelló, E. (2005). Transfer of tactical knowledge: From invasion games to floorball. Journal of Human Movement Studies, 49, 193-213.

Contreras, O. R., García-López, L. M., Gutiérrez, D., Del Valle, S., \& Aceña, R. M. (2007). Iniciación a los deportes de raqueta. La enseñanza de los deportes de red y muro desde un enfoque constructivista. Barcelona: Paidotribo.

Contreras, O. R., De la Torre, E., \& Velázquez, R. (2001). Iniciación Deportiva. Madrid: Síntesis. 
French, K. E., \& Thomas, J. R. (1987). The Relation of Knowledge Development to Children's Basketball Performance. Journal of Sport Psychology, 9(1), 15-32.

García-López, L. M., Contreras, O. R., Penney, D., \& Chandler, T. J. L. (2009). The role of transfer in games teaching: Implications in the development of the sports curriculum. European Physical Education Review, 15(1), 47-63. doi: 10.1177/1356336X09105211

González, S., García-López, L. M., Gutiérrez, D., \& Contreras, O. R. (2010). Estudio descriptivo sobre el desarrollo táctico y la toma de decisiones en jóvenes jugadores de fútbol (12 años). [Tactical awareness and decision making in youth soccer players (12 years): A descriptive study]. Infancia \& Aprendizaje, 33(4), 489-501.

Gréhaigne, J. F., Godbout, P., \& Boutier, D. (1997). Performance Assessment in Team Sports. Journal of Teaching in Physical Education, 16(4), 500-516. doi: 10.1177/0163278704267044

Griffin, L., Mitchell, S., \& Oslin, J. (1997) Teaching sport concepts and skills: A tactical games approach. Champaign, IL: Human Kinetics.

Griffin, L. L., Dodds, P., Placek, J. H., \& Tremino, F. (2001). Middle School Students' Conceptions of Soccer: Their Solutions to Tactical Problems. Journal of Teaching in Physical Education, 20(4), 314323.

Gutiérrez, D., González, S., García-López, L. M., \& Mitchell, S. (2011). Differences in decision-making development between expert and novice invasion game players. Perceptual and Motor Skills, 112(3), 871-888.

Gutiérrez, D. (2008). Desarrollo del pensamiento táctico en edad escolar [Development of tactical knowledge during scholar age] (Unpublished Ph.D.). University of Castilla-La Mancha, Ciudad Real.

Gutiérrez, D., García-López, L. M., \& Contreras, O. R. (2009, May). Relational nature of skills in invasion games. AIESEP International Seminar. Besançon, France.

Gutiérrez, D., García-López, L. M., González, S., \& Contreras, O. R. (2008, abril). Rendimiento de juego de alumnos de segundo de Educación Secundaria en un juego de invasión 5 versus 5. Paper presented at the IV Congreso Internacional y XXV Nacional de Educación Física, Córdoba. Retrieved from http://www.uco.es/IVCongresoInternacionalEducacionFisica/congres o/Documentos/001-203-517-004-001.html

Launder, A. G. (2001). Field invasion games. In Author, Play practice: the games approach to teaching and coaching sports (pp. 91-112). Ed: Champaign, IL: Human Kinetics.

MacPhail, A., Kirk, D., \& Griffin, L. (2008). Throwing and Catching as Relational Skills in Game Play: Situated Learning in a Modified Game Unit. Journal of Teaching in Physical Education, 27(1), 100115 .

Memmert, D., \& Harvey, S. (2008). The Game Performance Assessment Instrument (GPAI): Some Concerns and Solutions for Further Development. Journal of Teaching in Physical Education, 27(2), 220-240. $\quad$ Retrieved from http://journals.humankinetics.com/AcuCustom/SiteName/Documents /DocumentItem/15646.pdf

Memmert, D., \& Harvey, S. (2010). Identification of non-specific tactical tasks in invasion games. Physical Education and Sport Pedagogy, 15(3), 287-305. doi: 10.1080/17408980903273121

Mitchell, S. A., Oslin, J. L., \& Griffin, L. L. (2003). Sport Fundations for Elementary Physical Education. A Tactical Games Approach. Champaign, IL: Human Kinetics.

Nevett, M., Rovegno, I., Babiarz, M., \& McCaughtry, N. (2001). Changes in basic tactics and motor skills in an invasion-type game after a 12-lesson unit of instruction. Journal of Teaching in Physical Education, 20(4), 353-369.

Oslin, J. L., \& Mitchell, S. A. (2006). Game-centered approaches to teaching physical education. In M. O'Sullivan, D. Kirk, \& D Macdonald (Eds.), Handbook of Physical Education (pp. 627-650). Champaign, IL: Human Kinetics.

Oslin, J. L., Mitchell, S. A., \& Griffin, L. L. (1998). The game performance assessment instrument (GPAI): Development and preliminary validation. Journal of Teaching in Physical Education, $17(2)$
231-243.
Retrieved
from http://journals.humankinetics.com/AcuCustom/SiteName/Documents /DocumentItem/9810.pdf

Robles, J., Giménez, F. J., \& Abad. M. T. (2011). Metodología utilizada en la enseñanza de los contenidos deportivos durante la E.S.O. Revista Internacional de Medicina y Ciencias de la Actividad Física $y$ el Deporte, 10(41), 35-57. Retrieved from http://cdeporte.rediris.es/revista/revista41/artmetodologia201.pdf
Rovegno, I., Nevett, M., Brock, S., \& Babiarz, M. (2001). Teaching and learning invasion-game tactics in 4th grade: Introduction and theoretical perspective. Journal of Teaching in Physical Education, 20(4), 341-351.

Serra, J., García-López, L. M., \& Sánchez-Mora, D. (2011). El juego modificado, recurso metodológico en el fútbol de iniciación. Retos: Nuevas tendencias en Educación Física, Deporte y Recreación, 20, 37-42. $\quad$ Retrieved from http://www.retos.org/numero_20/RETOS\%2020\%2037-42.pdf

Vincent, W. (2005). Statistics in Kinesiology (3rd ed.). Champaign, IL: Human Kinetics. 